Mariusz Bartosiak

\title{
TOPOSY EUROPEJSKIEJ TRADYCJI PERFORMATYWNEJ. REKONESANS
}

\author{
Strategia milczącej wiedzy
}

\section{Wprowadzenie}

Taniec, szczególnie współczesny, stanowi jedno z najbardziej paradoksalnych i jednocześnie najdoskonalszych mediów komunikacji artystycznej. Z jednej strony niezwykłe bogactwo współczesnych form tańca i jego obecność we wszystkich niemal sferach egzystencji i kultury sprawiają wrażenie, jakby znacznie szybciej niż inne sztuki asymilował on nowe formy ruchu i ich choreograficzne sekwencje, zwielokrotniając w ten sposób swoje proliferacyjne możliwości. Z drugiej natomiast taniec najmocniej opiera się dyskursowi teoretycznemu, który w pełni wyjaśniłby jego istotę i pozwolił na opracowanie spójnej i wszechstronnie efektywnej metodologii badawczej. Jedna z przyczyn tego stanu rzeczy leży bez wątpienia $\mathrm{w}$ ścisłym związku tańca $\mathrm{z}$ ciałem, stanowiącym niezbywalne i wszechobecne medium naszej nie tylko artystycznej egzystencji. Poruszające się ciało jest zarówno tworzywem tej sztuki, jak i jej efektem artystycznym. Również ciało stanowi podstawę i główne medium procesów odbiorczych. Dokładniej, tym podstawowym medium jest system psychomotoryczny i powiązane $\mathrm{z}$ nim procesy przetwarzania. Badania neurokognitywne pokazują, że działanie tak rozumianego medium tańca zarówno inicjalnie (w odniesieniu do samych wewnętrznych bodźców ruchowych i zewnętrznych wizualnych oraz ich wstępnego przetwarzania), jak i w znacznej części wieloaspektowego, mentalnego opracowywania ( $w$ celu rozpoznania sensu i kształtowania podstaw do reakcji emocjonalnych) odbywa się poniżej progu świadomości i uwagi.

Wiedza tańca jest wiedzą milczącą, w znaczeniu, jakie nadał temu terminowi Michael Polanyi. W jego ujęciu milcząca wiedza przeciwstawiana jest wiedzy eksplicytnej, propozycjonalnej. Jest to wiedza, którą posiadamy i wiemy, że ją posiadamy, ale nie możemy jej wyrazić inaczej, jak tylko poprzez jej praktycznej wykorzystanie. Wiemy, jak coś zrobić, ale nie wiemy, jak to wyjaśnić, przynajmniej $\mathrm{w}$ formie dyskursywnej. Oczywiście zakres tak rozumianej wiedzy znacznie prze- 
kracza nawet szerokie rozumienie terminu „sztuka”, jednak praktyka artystyczna jest znakomitym przykładem obecności milczącej wiedzy. „Zasady sztuki mogą być użyteczne, ale nie determinują one praktyki artystycznej. Są to maksymy, które mogą służyć za przewodnika po sztuce tylko wtedy, gdy mogą być zintegrowane z praktyczną wiedzą o sztuce - nie mogą zastąpić tej wiedzy" (Polanyi 2002, s. 50).

Milcząca wiedza jest nie tylko trudna do wyartykułowania - jest $\mathrm{z}$ reguły podświadoma, a z pewnością przed-świadoma. Odzwierciedla się w ludzkich działaniach oraz $w$ ich interakcjach ze społecznym otoczeniem. Badania prowadzone na uniwersytetach australijskich pokazują, że nawet $75 \%$ wiedzy organizacyjnej ma charakter milczący (Chugh 2015, s. 129). Inaczej rzecz ujmując: milcząca wiedza jest nabywana poprzez uczestnictwo w kulturze; obok wiedzy dającej się sformułować, nabywamy również wiedzę niedającą się zwerbalizować, a jedynie zastosować w praktycznym działaniu: „cel umiejętnego performansu jest osiągany przez przestrzeganie zestawu regul, których osoba je stosująca nie zna jako takich" (Polanyi 2002, s. 49).

Milcząca wiedza jest przekazywana bezpośrednio między ludźmi, od mistrza do ucznia w praktyce. Jednak może być, przynajmniej częściowo, poddana wyjaśnieniu - wtedy ta wyrażona część przestaje być milcząca. Jednak nadal pozostaje obszar wiedzy, którą można przekazać tylko za pomocą bezpośrednio oddziałującej przykładowej praktyki. „Obserwując mistrza i naśladując jego starania w jego obecności, jego bezpośredni przykład, uczeń nieświadomie przejmuje zasady sztuki" (Polanyi 2002, s. 53). W ten sposób jedynym depozytariuszem milczącej wiedzy jest żywa tradycja, przekazywana uczniowi bezpośrednio przez mistrza. Taniec, a dokładniej tradycja i praktyka tańca, stanowi jeden z najlepszych przykładów „milczącej wiedzy” w działaniu.

\section{Historia tańca w Europie w kilku odsłonach}

Historia tańca w europejskiej tradycji performatywnej ma co najmniej kilka nieciągłych miejsc i przebiega w dających się wyodrębnić dwóch, względnie niezależnych nurtach. Jeden z nich sięga swoimi niewidocznymi już wyraźnie korzeniami ludowych, etnicznych tradycji performatywnych, które nadal zachowują swoje przedchrześcijańskie rysy. Drugi natomiast co najmniej od średniowiecza miał charakter dworski i w XVII wieku wykształcił balet, który od samego początku przeciwstawiany był pierwszemu (Cohen 2004). Oczywiście jest wiele przykładów mogących świadczyć o wzajemnych inspiracjach - są wśród nich wielkie dzieła baletowe czerpiące z ludowych motywów choreograficznych i muzycznych, a także „ludowe zespoły pieśni i tańca” (już w XX wieku), wykorzystujące w swoich pracach zarówno estetykę spektaklu baletowego, jak elementy jego techniki. Sytuację w XX wieku komplikuje taniec współczesny, który tworzy pewnego rodzaju trzeci nurt - narodził się on w opozycji do „sztuczności” baletu 
klasycznego (choć bardzo często czerpał z niego, szczególnie w zakresie przygotowania technicznego tancerzy), ale nie stanowił nigdy „tradycji ludowej” i, podobnie jak balet, był przede wszystkim sztuką metropolitalną (niemniej jednak zdarzało mu się współtworzyć „folklor miejski”, szczególnie wielkich miast).

Można oczywiście uznać ten stan rzeczy po prostu za wyraz bogactwa środków i motywów nowożytnego tańca europejskiego. Można również spojrzeć nieco głębiej w historię i wtedy okaże się, że europejska tradycja performatywna również $\mathrm{w}$ starożytności nie była jednolita. W pierwszym millenium rozdział przebiegał przede wszystkim na osi światopoglądowej (również ideologicznej) - z jednej strony mieliśmy do czynienia z „odwiecznymi”, przekazywanymi z pokolenia na pokolenie praktykami performatywnymi, które były nośnikami i podstawowymi „narzędziami” transmisji lokalnych tradycji światopoglądowych, $\mathrm{z}$ drugiej zaś z rozprzestrzeniającym się chrześcijaństwem, które dążyło do stopniowego opanowania starych lub wykształcenia nowych „narzędzi”, tak aby stały się nośnikami nowej wiary i nowego obrazu świata. Jeśli wziąć pod uwagę, że jest to bardzo złożony i powolny, stopniowy proces, to bez wątpienia jest on obecny również w nowożytności, choć w mniejszym stopniu. W ciągu ostatnich dwóch stuleci (od przełomu romantycznego do fali New Age) mamy dodatkowo do czynienia $\mathrm{z}$ różnymi, zarówno pod względem zasięgu, jak i efektywności, próbami „powrotu do źródel”, restytucji dawnych niechrześcijańskich tradycji kulturowych. W 1932 roku Gerardus van der Leeuw twierdzil, że „taniec jako funkcja życiowa w oczywistym i ścisłym związku z innymi przejawami naszego umysłu przestał istnieć", choć wcześniej podnosił poziom i intensywność życia (van der Leeuw 1978, s. 310, 315).

Z tym wymiarem historii związany jest „nieciągły” stosunek chrześcijańskich hierarchów do sztuk performatywnych w ogólności i do samego tańca. Istnieją pośrednie świadectwa obecności, a nawet oczywistej niezbywalności tańca w samej liturgii czy szerzej - w trakcie wykonywania obrządków religijnych w pierwszych stuleciach chrześcijaństwa, przynajmniej do IV wieku. Z historyczno-kulturowego punktu widzenia taki stan rzeczy nie jest dziwny - chrześcijaństwo ma bliskowschodnie korzenie, a taniec (również radosny, a więc niezbyt poważny) tradycyjnie pełnił w tych kulturach ważne funkcje religijne, był stałym elementem rytuałów (Davies 2004). Jednak z czasem zauważono, że taniec i jego tradycyjne choreografie mogą wnosić do chrześcijańskich praktyk element pogański, a ponadto nie są wystarczająco poważne (Lange 2009, s 16-19; Brooks 2004) - wprowadzano zatem różne obostrzenia lub wręcz zakazy. W efekcie w nowożytnym chrześcijaństwie taniec nie pełni funkcji religijnych (van der Leeuw 1978, s. 332-335, 347; Wagner 2004, s. 166-168), choć i pod tym względem istnieją nieliczne wyjątki praktyk spotykanych w różnych kościołach (van der Leeuw 1978, s. 320-321, 325-328; Wagner 2004, s. 168-169).

Z tymi bifurkacjami koresponduje rozpoznana przez Friedricha Nietzschego i ukształtowana w sztuce, a przede wszystkim w teatrze i dramacie starożytnej 
Grecji, opozycja między żywiołem dionizyjskim i apollińskim (Nietzsche 2001). Nietzsche uważał, że żywioły te były niegdyś w równowadze, jednak rozwój klasycznego dramatu greckiego spowodował narastającą dominację elementów apollińskich i jego delimitowanych rozumowo elementów sokratejskich, które pozbawiały go aury mistycznego uniesienia. Jednak najbardziej ubolewał nad odrzuceniem w kulturze greckiej żywiołu dionizyjskiego; ten trend został jego zdaniem spotęgowany przez kulturę chrześcijańską, bardzo przez niego krytykowaną. Żywioł dionizyjski był odpowiedzialny za żywotność i organiczność sztu$\mathrm{ki}$ osiągające swoje apogeum w orgiastycznym transie, uobecniającym grę życia i śmierci, również w jej jak najbardziej dosłownym sensie, co powodowało, że obcowanie ze sztuką dawało poczucie pełni życia. Na drugim biegunie sytuował apollińskie umilowanie formalnego piękna, harmonii i symetrii, abstrahujące od realiów życiowych i wprowadzające odbiorcę w rodzaj mistycznego upojenia, metafizycznego snu, który powodował całkowite oderwanie od biologicznych podstaw egzystencji. Zdegenerowaną, bo ograniczoną do czystej racjonalności i retorycznej klarowności, odmianą apollińskości w kulturze i sztuce był dla Nietzschego żywioł sokratejski. Najwyrazistszym i najgłębszym w swoich konsekwencjach przejawem tego historycznego (kulturowego i estetycznego) procesu było stopniowe pomniejszanie znaczenia i w efekcie zniknięcie tragediowego chóru, którego najstarsza, rytualna jeszcze choreo-grafia stanowiła najważniejszy nośnik i wyraz dionizyjskości sztuki. Sztuka ma osiągać swoją pełnię w nieustannej walce i względnej równowadze tych dwóch żywiołów, są one współzależne (Baran 2001, s. 10-11).

\section{Świat jest tańcem}

\section{W stronę kognitywnej antropologii tradycji performatywnej}

Nieciągłość (wynikająca z przerywanych linii bezpośredniego przekazu) i wielotorowość (związana z kształtującymi się nowymi paradygmatami kulturowymi) europejskiej tradycji performatywnej sprawiają, że różni się ona w istotny sposób od jej wschodnich odpowiedników, przynajmniej tych, które są dość dobrze opisane i które biorą czynny udział w kształtowaniu współczesnej, globalizującej się praktyki performatywnej, np. tradycji indyjskiej i japońskiej. Sytuacja skłania do zastosowania swego rodzaju porównawczej procedury hermeneutycznej, prowadzącej do wstępnego sformułowania kulturowego schematu poznawczo-performatywnego, kształtującego szersze, wrażliwe kulturowo ramy mentalne. Schemat ten z jednej strony obejmowałby dystynktywne cechy różnych tradycji performatywnych, z drugiej zaś pozwalałby (przynajmniej częściowo i nadal hipotetycznie) wypełniać luki lub wskazywać loci communes wariantywności w tradycji europejskiej. Powinien zatem stanowić performatywny odpowied- 
nik tego, co w językoznawstwie kognitywnym określa się jako „wyidealizowany model kognitywny", za pomocą którego porządkujemy naszą wiedzę (Lakoff 2011, s. 66), a w kulturoznawstwie kognitywnym jako „kulturową ramę interpretacyjną", czyli „ustrukturyzowane mentalne reprezentacje obszaru ludzkiego doświadczenia" (Kövecses 2011, s. 525). Jednocześnie powinien również zawierać generyczne składniki antropologiczne i estetyczne, kształtujące kulturowe wzorce antropologiczne i dyskursy estetyczne, odpowiedzialne za faktyczną, zmienną kulturowo praktykę performatywną. Centralnym składnikiem takiego schematu jest ogólna metafora „świat jest tańcem”, którą można określić jako szczególny rodzaj metafory schematyczno-wyobrażeniowej (por. Kövecses 2011, s. 195-196). Jest ona odpowiedzialna za elementarne dla danej tradycji performatywno-estetycznej postrzeganie człowieka i jego aktywności w świecie w kategoriach tańca i choreografii (zob. Kowalska 1991, s. 70-82; Kowalska 1995, s. 86-94). Derywaty tej ogólnej metafory stanowią podstawę dla postrzegania aktywności peformatywnej oraz wyobrażeniowy fundament dla konstruowania kulturowo warunkowanych reguł sztuki i estetyk. W szczególności jest ona odpowiedzialna za to, co w danej kulturze i tradycji performatywnej traktowane jest jako oczywiste, a zatem za wyobrażeniowe kształtowanie intencji wykonawczych oraz oczekiwań odbiorczych (z jakiego powodu? jak? w jakim celu?).

\section{Wyobrażeniowe źródła tradycji performatywnych Indii i Japonii}

W obu kulturach, indyjskiej i japońskiej, podstawowym wyobrażeniem kształtującym ich tradycje performatywne i estetyczne są mity tańczących bogów. W Indiach jest nim „kosmiczny taniec Śiwy”, w trakcie którego pokonuje niewiedzę i kreuje dynamiczną rzeczywistość (Kowalska 1991, s. 70-78; Ślósarska 1994, s. 55-59; Coomaraswami 2003, s. 83-95). W Japonii taniec Ameno-Uzume, Niebiańskiej Bystrej Dziewczyny, sprawia, że jakościowa charakterystyka rzeczywistości zjawiskowej ulega radykalnej przemianie (Kotański 1986a, s. 67-69 [1.21:36-131]; Kotański 1986b, s. 16-17; Kowalska 1995, s. 87-90). Obydwa wyobrażenia kształtują „oczywisty” sposób postrzegania tańca (jego istotę i celowość), a także innych form aktywności artystycznej. Jednak same wyobrażenia są radykalnie różne. W Indiach istota tańca (i sztuki w ogóle) wiązana jest $\mathrm{z}$ w pełni ustrukturowanym przedstawieniem całej rzeczywistości (Byrski 2007, s. 670), natomiast w Japonii skupiona jest na jakościowym, efemerycznym aspekcie rzeczywistości, a więc na niekompletności (Chang 2001, s. 63). Cel sztuki w obydwu tradycjach jest ściśle skorelowany z celami światopoglądowymi: w Indiach ostatecznym celem jest doświadczenie pełni rzeczywistości i wyzwolenie z okowów iluzji (Byrski 2007, s. 668, 671; Mishra 2006, s. 132-143), w Japonii - doświadczeniowa realizacja istoty rzeczywistości skrytej za jej zjawiskową powłoką i prawdziwej natury człowieka (Kozyra 2010, s. 17,29-76). W obydwu tradycjach podkreślany jest również soteriologiczny charakter samej aktywności 
twórczej - tak więc właściwie prowadzona aktywność artystyczna może prowadzić do efektów analogicznych z religijnymi (Haberman 2001; George 1999; Thornhill III 1993). Ponadto w obu tradycjach praktyki performatywne mają ścisły, bezpośredni praktyczny (Zarrilli 2004, s. 187-188) lub pośredni konceptualny związek ze sztukami walki (kalaripajatu jako składnik tradycji performatywnej kathakali w Indiach - Zarilli 2009, s. 63-80; estetyka zen jako wspólna podstawa japońskiej drogi sztuki gei-do, w której skład wchodzą m.in. sztuki performatywne oraz sztuki walki - Suzuki 2009, s. 54-140; Carter 2008, s. 21-50).

Takie dość znaczne, z konieczności bardzo schematyczne i silnie konceptualne uogólnienie ma na celu wprowadzenie odpowiednio szerokiej perspektywy i nie stanowi w najmniejszym stopniu podstawy do formułowania dalej i głębiej idących porównań obu tradycji. Są one pod każdym, nieco bardziej uszczegółowionym względem różne. Ponadto sugerowana homogeniczność tych tradycji dotyczy jedynie bardzo ogólnego charakteru właściwych dla nich schematów wyobrażeniowych i wynikających z nich bardzo ogólnych koncepcji estetyczno-antropologicznych. W żaden sposób nie próbuje ograniczać bogactwa i różnorodności form i gatunków performatywnych ani jednolitości czy pełnej zgodności prowadzonych $\mathrm{w}$ tych tradycjach dyskursów estetycznych - również pod tym względem są to tradycje wewnętrznie bardzo zróżnicowane i bogate.

\section{Antyczne korzenie nowożytnych tradycji performatywnych w Europie}

Historia tańca i sztuk performatywnych w Europie nie daje podstaw do formułowania tezy o podobnie homogenicznych kulturowo i antropologicznie wyobrażeniach, nawet na równie znacznym stopniu uogólnienia. Jednak przedstawiony schemat pozwala postawić pytanie o możliwość istnienia w europejskiej tradycji performatywnej schematu lub schematów o podobnie wszechstronnym antropologicznie charakterze. Czy w mitologicznym dziedzictwie europejskim znajdziemy źródłowe dla sztuki i filozofii człowieka wyobrażenia tańca? Czy sztuka europejska kiedykolwiek miała jakiś poznawczo-performatywny wzorzec soteriologiczny? Czy istniała równie ścisła korelacja estetyki, epistemologii i metafizyki? Czy wreszcie sztuki walki miały w europejskiej tradycji związek z soteriologią i sztukami performatywnymi? Zanim jednak postawię kilka hipotez mogących stanowić odpowiedź na te i podobne pytania, przyjrzyjmy się wybranym antycznym źródłom sztuki i estetyki nowożytnej.

Najstarszą znaną nam teorię estetyczną, soteriologiczną i metafizyczną przypisuje się Pitagorasowi i jego szkole. Korelację tych trzech dziedzin zapewnia koncepcja liczby, miary i proporcji - to one są źródłem harmonii przenikającej wszystkie sfery rzeczywistości. Później również Platon twierdzil, że liczba stanowi najwyższy stopień poznania, a matematyka stanowi swego rodzaju język rozumu poszukującego świata idei. Badania matematyczne prowadzone $w$ kręgach pitagorejskich stały się podstawą estetycznych kanonów klasycznej sztuki greckiej. 
Pitagorejczycy upowszechniali również orfickie przekonanie, że celem człowieka jest oczyszczenie duszy z więzów ciała (pozbycie się elementów chtonicznych na rzecz uranicznych), a temu miała służyć między innymi sztuka (Tatarkiewicz 1985, s. 57-95, 115-138). W późniejszych czasach ta perspektywa nie miała już tak istotnego wplywu na koncepcje epistemologiczne i soteriologiczne - chrześcijaństwo przyniosło w tym względzie odmienną wizję. Jednak w sztuce (głównie architekturze, malarstwie, rzeźbie i muzyce) ostatnich dwóch tysiącleci jest wiele realizacji odnoszących się pośrednio lub bezpośrednio do pitagoreizmu. Najmniej wiemy współcześnie o greckich sztukach walki i ich związkach z koncepcjami światopoglądowymi.

Kolejnym interesującym tropem jest pochodzenie teatru i sztuk widowiskowych. Ich powstanie wiązane jest $\mathrm{z}$ rytuałami religijnymi, a te z kolei są skorelowane $\mathrm{z}$ wyobrażeniami mitycznymi. Istnieje wspólny, czysto konceptualny motyw, który jest obecny w trzech wielkich kulturach basenu Morza Śródziemnego - celebracja oraz naśladowanie śmierci i zmartwychwstania boga. Oczywiście podobieństwa istnieją jedynie na bardzo ogólnym, zorientowanym antropologicznie i estetycznie poziomie - każde uszczegółowienie, zwłaszcza w kontekście religijnym, prowadzi do nieredukowalnych różnic.

W starożytnym Egipcie najbardziej okazałe rytualne widowiska były związane z pasją Ozyrysa, który w wyniku spisku zazdrosnego brata Seta został poćwiartowany, a jego rozrzucone szczątki odnalazła (z wyjątkiem fallusa) i złożyła w całość jego siostra Izyda. Na skutek jej zabiegów Ozyrys zmartwychwstał. Uroczystości trwały 15 dni, jednak tylko pięć ostatnich miało publiczny, otwarty charakter. Otwierała je Procesja Szakala Otwierającego Drogę (Wepwawet) - uliczna bijatyka zwolenników Ozyrysa i Seta, zakończona sukcesem tych pierwszych. Drugi dzień to Wielka Procesja Ozyrysa - „ciało Ozyrysa” zostaje przeniesione na barce Neszmet (barka, na której co noc podróżuje Re) ze świątyni do grobu. Trzeci dzień - Opłakiwanie Ozyrysa i unicestwienie wrogów kraju; kontynuowane są lamentacje, rozpoczęte poprzedniej nocy przez Izydę i Neftydę. Dzień czwarty - Nocne czuwanie: modlitwy i recytacje świętych tekstów podczas pochówku. Piątego dnia następuje Zmartwychwstanie Ozyrysa: o świcie Ozyrys zmartwychwstaje - jego posąg jest triumfalnie niesiony z powrotem do świątyni. Mit pasji Ozyrysa należy do grupy mitów wegetatywnych, opisujących cykliczne odradzanie się całej natury - Ozyrys personifikuje niezniszczalną moc życia. W soteriologii egipskiej podkreśla się ostateczne zjednoczenie duszy z Ozyrysem (Niwiński 1995, s. 196-223; Przybyłek 2012).

Na związek misteriów dionizyjskich z teatrem wskazuje już Arystoteles w swojej Poetyce. Dionizos to uosobienie bios, „siły życiowej” obecnej w całej naturze, a jego misteria to cykl inicjacyjny i oczyszczający nieświadomość. Był nazywany „bogiem podwójnie zrodzonym”. Istnieje wiele opowieści mitycznych, których jest bohaterem, jednak jedna z nich, szczególnie związana z misteriami na jego cześć, ma pewne cechy wspólne z mitem ozyriańskim. Na rozkaz Hery, 
zazdrosnej o miłostki męża, a szczególnie o ich owoce, tytani porwali nowo narodzonego syna Zeusa, Dionizosa - dziecię rogate, wieńczone wężami - i mimo jego przeobrażeń (koziol, byk, wąż, jeleń, osiol, dzikie koty) rozszarpali go na kawałki. Następnie gotowali rozerwane ciało w kotle, tam zaś, gdzie spadły krople krwi Dionizosa, wyrosły drzewa granatu. Uratowała go jednak i scaliła z powrotem jego babka Rea (żona Kronosa), po czym Dionizos zmartwychwstaf (Graves 1982, s. 102-108; Kerényi 1997, s. 58-87, 231-277; Sieradzan 2007, s. 159-185). Również mit Dionizosa jest mitem wegetacyjnym. W starożytnej Grecji jedno z powszechnych przekonań co do celu ludzkich dążeń (choć należy pamiętać o intensywnej aktywności i popularności różnych greckich szkół filozoficznych, które prezentowały różne stanowiska) znalazło swój wyraz wśród sentencji zdobiących świątynię Apollina w Delfach: gnoti sea outon, czyli „poznaj samego siebie". Podobną myśl zawarł również Arystoteles w swojej Poetyce, gdy opisywał modelową sekwencję zdarzeń tragicznych zwieńczonych anagnorisis (samopoznaniem protagonisty) (zob. Arystoteles 1989, s. 45-50; Podbielski 1989, s. LXXXIII-LXXXIV).

Trzecia odsłona tego performatywnego motywu mitycznego nastąpiła w średniowiecznej Europie u schyłku pierwszego tysiąclecia po Chrystusie. Początkowo w formie dramatyzacji liturgicznych, skupionych wokół misterium wielkanocnego. Pierwsza teatralizacja mszy miała bardzo skromny charakter - zaczynała się od donośnego pytania aniołów strzegących grobu Chrystusa:

Kogo szukacie w grobie, o Chrześcijanki?

Jezusa Nazareńskiego ukrzyżowanego, o mieszkańcy nieba.

Nie ma Go tu. Zmartwychwstal, jak zapowiedział.

Idźcie i głoście, że powstał z grobu.

Zmartwychwstałem...

Po czym następował właściwy początek mszy wielkanocnej (Kocur 2010, s. 105).

Te bardzo skromne początki w ciągu kolejnych stuleci rozwinęly się i formalnie, i treściowo. Wkrótce wykształciło się pięć różnych pod względem formy i zakresu prezentowanych treści gatunków teatralnych. Same misteria rozrosły się do cykli trwających wiele dni. Rozwijały motyw działań dramatycznych prowadzących do wyzwolenia człowieka za sprawą pasji Chrystusa (Wiles 1999, s. 65-92; Dąbrówka 2001, s. 385-546; Kocur 2010, s. 67-140). Jest to oczywiście mit soteriologiczny radykalnie różniący się od dwóch wcześniej opisanych. Zauważmy jednocześnie, że ten właśnie aspekt typologiczny - przy wszystkich różnicach religijnych - jest wspólny ze wskazanymi mitami wschodnimi.

Można $\mathrm{w}$ tym miejscu postawić hipotezę, że śródziemnomorska tradycja performatywna związana jest od tysiącleci z motywem pasji, stanowiącym jej wyobrażeniową milczącą wiedzę, co wyraźnie odróżnia ją od tradycji wschod- 
nich, w których można znaleźć podobne pasyjne motywy mityczne, jednak nie one stały się wyobrażeniowym źródłem sztuk performatywnych. Znaczący jest fakt, że motyw ten przetrwał radykalne przemiany, obejmujące wszystkie aspekty kultury (religijne, filozoficzne, antropologiczne, estetyczne, polityczne). Trudno szukać takiego fenomenu we względnie ciągłych, szczególnie w zestawieniu ze śródziemnomorską, tradycjach performatywnych Indii i Japonii.

Kolejna hipoteza, bazująca jednak na bardziej sfragmentowanych historycznie praktykach i wyobrażeniach, wiąże się z zauważalnymi opozycjami kształtującymi europejską tradycję performatywną. W istocie należałoby raczej myśleć o dwóch skorelowanych ze sobą toposach performatywnych realizujących przeciwstawiane sobie schematy.

\section{Topos Ofiarnika. Tradycja pasji i samoofiarowania}

Obok przywołanego powyżej przekazu ewangelicznego tradycja przekazała współczesności wyobrażenie zawarte w pochodzącym z drugiego wieku i przypisywanym św. Janowi Ewangeliście apokryfie Dzieje Jana. Znajduje się w nim Hymn Chrystusa Tańczącego:

Nim jednak Jezus został pochwycony ( ... ), zgromadziwszy nas wszystkich, powiedział: „Zanim Mnie im wydadzą, zaśpiewajmy hymn Ojcu, i tak wyjdziemy naprzeciw temu, co ma nastąpić”. Kazał więc nam uczynić krąg, chwycić się nawzajem za ręce. On sam zaś stanął po środku i rzekł: „Odpowiadajcie mi Amen”. I zaczął wtedy śpiewać hymn (Starowieyski 2007, s. 305-308).

Mamy więc w tradycji europejskiej soteriologiczne wyobrażenie tańczącego Boga, jednak nie zostało ono włączone do ksiąg kanonicznych i pozostało na obrzeżach kultury. Jest $w$ tym apokryfie zawarta sugestia, że opisany w nim taniec, obejmujący również uczniów jako tańczących współuczestników, ma również dla nich charakter autosoteriologiczny: „Odpowiadając na mój taniec, zobacz siebie we Mnie” (Starowieyski 2007, s. 308).

Do tego toposu nawiązał w swoich poszukiwaniach i praktykach performatywnych Jerzy Grotowski, formułując koncepcję sztuki jako wehikułu, teatru ubogiego (skupionego na fenomenie spotkania performera i świadka), aktu całkowitego (rozumianego w kategoriach samoofiarowania) i aktora ogołoconego (dążącego do „rzeczywistej prawdy o sobie”) - (Grotowski 1999).

Ponieważ topos ten jest oparty na organicznym związku z naturą ludzką, a przez to również z naturą jako taką, należy zaliczyć do niego również wszelkiego typu praktyki odwołujące się do mitów wegetacyjnych (nie tylko soteriologicznych). Jest on zatem realizowany przez całą tradycję tańca ludowego i etnicznego, a także różnorodne nawiązania do tej tradycji w tańcu współczesnym, jak np. organiczny taniec Izadory Duncan (Cohen 2004, s. 130) czy Święto Wio- 
sny Mikołaja Roericha, Igora Strawińskiego, Siergieja Diagilewa i Wacława Niżyńskiego.

Charakterystyczną cechą tego toposu jest (jak dotychczas) prawie całkowity brak wymiaru konceptualnego - koncepcja tańca i aktorstwa organicznego nadal czeka na swoje teoretyczne opracowanie, które mogłoby się stać podstawą spójnej metodologii badawczej. Podstawy teorii aktorstwa psychofizycznego, choć jedynie w oparciu o wschodnie praktyki performatywne i ich konteksty kulturowe, zaproponował Philip Zarilli (Zarilli 2009).

\section{Topos Zdobywcy (Wojownika). Tradycja abstrakcyjnego rozumu}

Drugi topos opiera się tradycji pitagorejskiej z jej arytmetyczno-geometrycznymi idealizacjami, wobec których konceptualizowane są schematy antropologiczne, estetyczne i metafizyczne (o których już wspominałem). W obrębie tego toposu należy umiejscowić nieprzedstawiające choreografie dworskie (McGowan 2004; Christout 2004) oraz oczywiście klasyczny balet (Cohen 2004, s. 130). W ramach tej tradycji mieszczą się również wszystkie współczesne choreografie podporządkowujące taniec wyidealizowanym formom i liniom geometrycznym, poczynając od Baletu Triadycznego Oskara Schlemmera, zrealizowanego w ramach programu Bauhausu (Schlemmer 2010).

Osobną grupą praktyk kulturowych, którą należy objąć zakresem tego toposu, jest zrodzona w późnym średniowieczu „sztuka szpady”, europejska sztuka walki o podobnym do dalekowschodniej schemacie autosoteriologicznym, wpisanym jednak w oryginalną, europejską tradycję pitagorejską, rozwijaną w średniowieczu pod szyldem „świętej geometrii” i hermetyzmu. Większość podręczników fechtunku i innych form walki była skupiona jedynie na technikach unikania i zadawania skutecznych sztychów (zob. Clements, Hull 2008), co oczywiście tylko pozornie pozwala na zaliczenie ich do konceptualnych schematów toposu wojownika. Dwa dzieła zasługują wszakże na szczególną uwagę: The Philosophy of Arms, of its art and the Christian Offense and Defense Jeronimo de Carranzy z 1582 roku oraz Academy of the Sword Gerarda Thibaulta z 1630 roku. Obaj autorzy wpisują techniki i choreografie szermiercze w precyzyjnie dobrane (w oparciu o zasady „świętej geometrii”) figury i bryły geometryczne, a co najważniejsze - traktują szermierkę (wraz ze skorelowanymi z nią konceptualizacjami geometrycznymi) przede wszystkim jako narzędzie do kształtowania pełni człowieczeństwa i samodoskonalenia przez tak schematyzowaną sztukę szpady (Greer 2015).

Należy podkreślić, że również w obrębie tego toposu istnieją istotne różnice wynikające $\mathrm{z}$ aktualizacji różnych schematów. O ile w średniowieczu, renesansie i jeszcze w baroku „święta geometria” i „sztuka szpady” traktowały (zgodnie z głęboką tradycją pitagorejską i późniejszą hermetyczną) arytmetyczno-geometryczne idealizacje jako inherentne w człowieku i kosmosie, o tyle już od tańców 
dworskich, poprzez balet klasyczny do koncepcji schlemmerowskich, schematy skupiały się na wpisaniu człowieka i kosmosu w te idealizacje. O ile zatem pierwotna geometryzacja miała charakter organiczny, immanentny, o tyle jej nowożytne interpretacje zakładały ich abstrakcyjne oderwanie od rzeczywistości człowieka i kosmosu.

\section{Wnioski. Tańcząc milczącymi światami}

Przedstawione rozważania stanowią raczej wstępny rekonesans, a poruszona w nich problematyka wymaga dalszych badań. Same toposy traktuję jako ledwie widoczny fragment znacznie większej, niewyjaśnionej całości. Dotyczy to zarówno szczegółowych danych, przede wszystkim historycznych, jak i schematów poznawczo-wyobrażeniowych, które zostały jedynie wskazane. Istotną cechą przedstawionej perspektywy jest jej zdecydowanie nielinearny charakter. Wskazane toposy od greckich początków (a pewnie znacznie wcześniejszych, co mogłyby zweryfikować dalsze badania prowadzone w tym kierunku) wchodzą ze sobą w nieustanną, dynamiczną interakcję, która jako taka również powinna zostać poddana dokładniejszemu oglądowi. Dynamika tej wieloaspektowej interakcji dotyczy bowiem nie tylko samego tańca (jego szeroko rozumianych poetyki i estetyki), ale również jego korelacji z innymi obszarami kultury, w których różne aspekty tej dynamiki są obecne, przy czym ta obecność może mieć wyrazisty lub „milczący” charakter.

W podsumowaniu można pokusić się o kilka konkluzji, jakich może dostarczyć takie wstępne zarysowanie problemu. William C. Reynolds zauważa, że charakterystyczne dla rozwoju europejskich tradycji „skupienie na komunikacji zewnętrznej odsuwa taniec od jego korzeni w głęboko osobistym doświadczeniu" (Reynolds 2004, s. 559), ponadto również w perspektywie diachronicznej wyraźnie zaznacza się tendencja do jedynie abstrakcyjnego traktowania koncepcji arytmetyczno-geometrycznych, które jeszcze kilkaset lat temu miały charakter immanentny (John Dee używał w tym kontekście nazwy „antropografia” - zob. Yates 1969, s. 190). Współczesna organiczność w sztukach performatywnych zbyt często dąży do deprywacji ciała (której w tradycjach wschodnich zapobiegają np. sztuki walki i związek z doskonaleniem wewnętrznym), pozbawionego wyrazistych antropologicznie i teleologicznie schematów. I wreszcie - szczególnie wyraźna w przyjętej perspektywie porównawczej staje się luka między śródziemnomorską tradycją performatywną a tańcem współczesnym, obejmująca zarówno schematyzacje pojęciowe, jak i wyobrażeniowe. A zatem $\mathrm{z}$ jednej strony istnieje konieczność wypracowania na wskroś współczesnej, wszechstronnej teorii i efektywnej analitycznie metodologii. Z drugiej zaś potrzebujemy dobrej metafory, która przywróci nam wizję pełni samego tańca i naszego w nim bycia - na ten brak pełni kierował uwagę przywoływany już van der Leeuw w 1932 roku i pięć lat później Curt Sachs, gdy konstatował, że: „Kiedy w wyższych kulturach 
taniec staje się sztuką $\mathrm{w}$ węższym sensie, kiedy staje się spektaklem, kiedy szuka raczej wpływu na ludzi niż na duchy, wtedy jego uniwersalna moc jest rozbita” (cyt. za Reynolds 2004, s. 559). Tę samą myśl można ująć wyobrażeniowym pytaniem: czy spychany na apokryficzne obrzeża Tańczący Chrystus może być współczesny?

\section{Bibliografia}

Arystoteles (1989), Poetyka, przeł. i oprac. H. Podbielski, Zakład Narodowy im. Ossolińskich, Wrocław.

Baran B. (2001), Metafizyka tragedii, [w: ] F. Nietzsche, Narodziny tragedii albo Grecy i pesymizm, tłum. B. Baran, Wydawnictwo Baran i Suszczyński, Kraków.

Brooks L.M. (2004), Christianity and Dance. Medieval Views, [w: International Encyclopaedia of Dance, t. 2, S.J. Cohen (red.), Oxford University Press, New York-Oxford.

Byrski K.M. (2007), Indyjski teatr i dramat klasyczny, [w: ] M. Mejor (red.), Światto stowem zwane. Wypisy z literatury staroindyjskiej, Wydawnictwo Akademickie Dialog, Warszawa.

Carter R.E. (2008), The Japanese Arts and Self-Cultivation, State University of New York Press, Albany.

Chang Ch.-Y. (2001), Ogólne pojęcie piękna, [w:] K. Wilkoszewska (red.), Estetyka japońska. Antologia, t. 1: Wymiary przestrzeni, Universitas, Kraków.

Chirstout M.-F. (2004), Ballet de Cour, 1643-1685, [w: ] International Encyclopaedia of Dance, t. 1, S.J. Cohen (red.), Oxford University Press, New York-Oxford.

Chugh R. (2015), Do Australian Universities Encourage Tacit Knowledge Transfer?, [w: ] Proceedings of the $7^{\text {th }}$ International Joint Conference on Knowledge Discovery, Knowledge Engineering and Knowledge Management, DOI: 10.5220/0005585901280135.

Clements J., Hull J. (red.) (2008), Masters of Medieval and Renaissance Martial Arts. Rediscovering the Western Combat Heritage, Paladin Press, Boulder (CO).

Cohen S.L. (2004), Genres of Western Theatrical Dance, [w: International Encyclopaedia of Dance, t. 3, S.J. Cohen (red.), Oxford University Press, New York-Oxford.

Coomaraswami A. (2003), The Dance of Shiva, Munchiram Manoharlal, New Delhi.

Davies J.G. (2004), Christianity and Dance. Early Christian Views, [w: ] International Encyclopaedia of Dance, t. 2, S.J. Cohen (red.), Oxford University Press, New YorkOxford.

Dąbrówka A. (2001), Teatr i sacrum w średniowieczu, Fundacja Na Rzecz Nauki Polskiej, Wydawnictwo FUNNA, Wrocław.

George D.E.R. (1999), Buddhism as/in Performance. Analysis of Meditation and Theatrical Practice, D.K. Printworld, New Delhi.

Graves R. (1982), Mity greckie, tłum. H. Krzeczkowski, PIW, Warszawa.

Greer J.M. (2015), Swordsmanship and Esoteric Spirituality: An Introduction to Gerard Thibault's Academie de l'Espée, [w:] M.A. DeMarco (red.), Medieval Warrior Cultures of Europe and Japan, Via Media, Santa Fe (NM).

Grotowski J. (1999), Teksty z lat 1965-1969, J. Degler, Z. Osiński (red.), Wydawnictwo Uniwersytetu Wrocławskiego, Wrocław. 
Haberman D.L. (2001), Acting as a Way of Salvation, Motilal Banarsidass, New Delhi.

Kerényi K. (1997), Dionizos. Archetyp życia niezniszczalnego, tłum. I. Kania, Wydawnictwo Baran i Suszczyński, Kraków.

Kocur M. (2010), Drugie narodziny teatru. Performanse mnichów anglosaskich, Wydawnictwo Uniwersytetu Wrocławskiego, Wrocław.

Kotański W. (1986a), Kojiki czyli Księga Dawnych Wydarzeń, t. 1: Tekst i indeksy, tłum. W. Kotański, PIW, Warszawa.

Kotański W. (1986b), Kojiki czyli Księga Dawnych Wydarzeń, t. 2: Przypisy, tłum. W. Kotański, PIW, Warszawa.

Kövecses Z. (2011), Język, umyst, kultura. Praktyczne wprowadzenie, tłum. A. KowalczePawlik, M. Buchta, Universitas, Kraków.

Kowalska J. (1991), Taniec drzewa życia. Uniwersalia kulturowe w tańcu, Instytut Historii Kultury Materialnej PAN, Warszawa.

Kowalska J. (1995), Koło bogów. Ruch i taniec w mitach i obrzędach, Instytut Archeologii i Etnologii PAN, Warszawa.

Kozyra A. (2010), Estetyka zen, TRIO, Warszawa.

Lakoff G. (2011), Kobiety, ogień i rzeczy niebezpieczne. Co kategorie mówią nam o umyśle, E. Tabakowska (red.), tłum. M. Buchta, A. Kotarba, A. Skucińska, Universitas, Kraków.

Lakoff G., Turner M. (1989), More Than Cool Reason: a field guide to poetic metaphor, University of Chicago Press, Chicago-London.

Lange R. (2009), O istocie tańca i jego przejawach w kulturze. Perspektywa antropologiczna, Instytut Choreologii w Poznaniu, Poznań.

van der Leeuw G. (1978), Czy w niebie tańcza??, tłum. A. Wojtaś, „Literatura na Świecie”, nr $5(85)$.

McGowan M.M. (2004), Ballet de Cour, 1560-1670, [w: International Encyclopaedia of Dance, t. 1, S.J. Cohen (red.), Oxford University Press, New York-Oxford.

Mishra D.L. (2006), Aesthetic Philosophy of Abhinavagupta, Kala Prakashan, Varanasi.

Nietzsche F. (2001), Narodziny tragedii albo Grecy i pesymizm, tłum. B. Baran, Wydawnictwo Baran i Suszczyński, Kraków.

Niwiński A. (1995), Mity i symbole starożytnego Egiptu, PRO-EGIPT, Warszawa.

Podbielski H. (1989), Wstęp, [w: ] Arystoteles, Poetyka, tłum. i oprac. H. Podbielski, Zakład Narodowy im. Ossolińskich, Wrocław.

Polanyi M. (2002), Personal Knowledge: Towards a Post-Critical Philosophy, Routledge, London.

Przybyłek M. (2012), Misteria ozyriańskie - widowisko czy rytuat?, „Collectanea Philologica”, t. XIV.

Reynolds W.C. (2004), European Traditional Dance, [w:] International Encyclopaedia of Dance, t. 2, S.J. Cohen (red.), Oxford University Press, New York-Oxford.

Schlemmer O. (2010), Eksperymentalna scena Bauhausu. Wybór pism, oprac. M. Leyko, Słowo/obraz terytoria, Gdańsk.

Sieradzan J. (2007), Szaleństwo $w$ religiach świata. Szamanizm, religia starogrecka, judaizm, chrześcijaństwo, hinduizm, buddyzm, islam, Inter Esse Wydawnictwo Wanda, Kraków. 
Starowieyski M. ks., (red.) (2007), Dzieje Jana, tłum. ks. M. Starowieyski, [w: ] Apokryfy Nowego Testamentu, t. 2: Apostołowie, cz. 1: Andrzej, Jan, Pawet, Piotr, Tomasz, ks. M. Starowieyski (red.), WAM, Kraków.

Suzuki D.T. (2009), Zen i kultura japońska, tłum. B. Szymańska, P. Mróz, A. Zalewska, Wydawnictwo Uniwersytetu Jagiellońskiego, Kraków.

Ślósarska J. (1994), Mistyczne i archetypiczne obrazy kosmosu, WN Semper, Warszawa. Tatarkiewicz W. (1985), Historia estetyki, t. 1, Arkady, Warszawa.

Thornhill III A.H. (1993), Six Circles, One Dewdrop. The Religio-Aesthetic World of Komparu Zenchiku, Princeton University Press, Princeton (NJ).

Wagner A. (2004), Christianity and Dance. Modern Views, [w:] International Encyclopaedia of Dance, t. 2, S.J. Cohen (red.), Oxford University Press, New York-Oxford.

Wiles D. (1999), Teatr w Rzymie i chrześcijańskiej Europie, [w: ] J.R. Brown (red.), Historia teatru, tłum. H. Baltyn-Karpińska, Diogenes / Świat Książki, Warszawa.

Yates F.A. (1969), Theatre of the World, Routledge and Kegan Paul, London.

Zarrilli Ph. (2004), Asian Martial Arts, [w: International Encyclopaedia of Dance, t. 2, S.J. Cohen (red.), New York-Oxford: Oxford University Press.

Zarrilli Ph. (2009), Psychophysical Acting. An Intercultural Approach after Stanislavski, Routledge, London-New York.

\section{Summary}

Paper explores the problem of „tacit knowledge” (M. Polanyi), which is applied to the European dance tradition. Theoretical background is supplemented by chosen issues of cognitive approach to linguistics, literature and culture (G. Lakoff, M. Turner). Mythical, aesthetic and anthropological basics of Indian and Japanese performative traditions are compared to the chosen issues of religious, aesthetic and anthropological foundations of European tradition. Intercultural comparison leads to the hypothesis of two main cognitive-performative topoi and two lineages within Mediterranean performative tradition: Topos of Self-Sacrificer or the Lineage of (Organic) Passion, and Topos of Conqueror (Warrior) or the Lineage of Abstract Reason. 